\title{
Grazzini y Cervantes. Notas sobre una relación poco conocida
}

\author{
ABRAHAM MADROÑAL ${ }^{*}$
}

\section{Resumen}

Se presentan algunos paralelos entre obras escritas por el autor italiano Anton Francesco Grazzini (1505-1584) y Cervantes. En especial, se aportan algunos lugares concretos en poesías, novelas y obras de teatro de Grazzini que guardan relación con otras obras de Cervantes, lo que convierte al italiano en una probable fuente del autor del Quijote.

Palabras Clave: Anton Francesco Grazzini; fuente cervantina; poesía burlesca; novelas; Persiles.

\section{Title: Grazzini and Cervantes. Notes on an unsuspected relationship}

\begin{abstract}
In this paper we will present some parallels in poetry, novels ant theatre between works of the Italian Anton Francesco Grazzini (1505-1584) and Cervantes. This relationship between the two authors turns Grazzini into a possible source for the Quixote's author.

Key Words: Anton Francesco Grazzini; Cervantine source; burlesque poetry; novels; Persiles.

\section{Cómo citar este artículo / Citation}

Madroñal, Abraham (2017). «Grazzini y Cervantes. Notas sobre una relación poco conocida», Anales Cervantinos. 49, pp. 393-400, doi: http://dx.doi.org/10.3989/anacervantinos.2017.015.
\end{abstract}

* Director, Anales Cervantinos. abraham.madronal@cchs.csic.es / ORCID iD: http://orcid. org/0000-0002-5880-9668. 
Pretendo dar cuenta en estas líneas que siguen de una fuente cervantina no demasiado mencionada, la del poeta, novelista y dramaturgo italiano Anton Francesco Grazzini, que no se suele citar entre los autores que influyen en Cervantes y sin embargo comparte con este más de una circunstancia. En efecto, Anton Francesco Grazzini, il Lasca (Florencia, 1505-1584), es, como el autor del Quijote, un ingenio lego, más bien autodidacta, que también - como el autor español - se burló de los pedantes latinistas y helenistas y prefirió la lengua romance al latín; además, fue maestro en el uso de la ironía y la burla. Escritor amigo de academias, fundó en 1540 la Accademia degli Umidi, aunque fue expulsado de ella, se nos dice, por sus ideas anticlásicas; y es también uno de los fundadores de la famosa Accademia della Crusca ${ }^{1}$.

Grazzini es sobre todo conocido por una colección de novelas, Le Cene (1549), al estilo del Decameron boccacciano, y por sus siete comedias, todas anteriores a 1566: La gelosia (1551), La spiritata (1560), La strega, La sibilla, La pinzochera, I parentadi, L'arzigogolo. Muy pocas se representaron en vida, pero la que aquí nos interesa especialmente, La spiritata, se representó en Bolonia y luego en Florencia, durante el carnaval de 1560. También es autor de buen número de poesías, muchas de ellas de carácter jocoso 2 .

Sabemos que Cervantes deambula por Italia entre 1569 y 1571 , y que en compañía del cardenal Acquaviva, pasa varias veces por la ciudad de los Médici. Acaso también por Luca, para la que guarda un recuerdo agradecido, por lo bien que acogía a los españoles, según refleja en dos de sus obras, como veremos.

\section{LOS POEMAS}

Quizá la primera relación haya que establecerla entre los poemas, especialmente los burlescos, en los que tanto Grazzini como Cervantes eran expertos consumados (Werner 1973; Martin 1991). Precisamente, uno de los sonetos de la supuesta academia de Argamasilla, que Cervantes publica en la primera parte del Quijote, concretamente el que corresponde al «Caprichoso, discretísimo académico de la Argamasilla, en loor de Rocinante, caballo de don Quijote de la Mancha», termina con el terceto que dice:

Nunca sus glorias el olvido mancha, pues hasta Rocinante en ser gallardo excede a Brilladoro y a Bayardo (Cervantes, Quijote, 2015, p. 651).

1. Para la biografía de este autor, puede verse la «Vita del Lasca», incluida en Le Cene, 1857. Más recientemente, Zampini (2013).

2. Para una bibliografía actualizada sobre el autor, que también escribió otro tipo de textos, véase Pignatti (2014). 
Y justamente en un soneto de Grazzini dedicado a su admirado Barchi se habla de una «bestiazzia stravagante e piazza» que «al portante, al galoppo, al passo, al trotto / sembra, tanto si stroze o si disguazza / l' alfana già di Dodon della Mazza / o la giumenta del Piovano Arlotto». Y además:

destro, animoso, leggero e gagliardo

come fur già Brigladoro e Baiardo (Grazzini, Rime, 2015, p. 32).

He aquí los poemas completos de ambos autores:

\begin{tabular}{|c|c|}
\hline Cervantes & Grazzini \\
\hline $\begin{array}{l}\text { En el soberbio trono diamantino } \\
\text { que con sangrientas plantas huella Marte, } \\
\text { frenético el Manchego su estandarte } \\
\text { tremola con esfuerzo peregrino, } \\
\text { cuelga las armas y el acero fino } \\
\text { con que destroza, asuela, raja y parte... } \\
\text { ¡Nuevas proezas!, pero inventa el arte } \\
\text { un nuevo estilo al nuevo paladino. } \\
\text { Y si de su Amadís se precia Gaula, } \\
\text { por cuyos bravos descendientes Grecia } \\
\text { triunfó mil veces y su fama ensancha, } \\
\text { hoy a Quijote le corona el aula } \\
\text { do Belona preside, y dél se precia, } \\
\text { más que Grecia ni Gaula, la alta Mancha. } \\
\text { Nunca sus glorias el olvido mancha, } \\
\text { pues hasta Rocinante, en ser gallardo, } \\
\text { excede a Brilladoro y a Bayardo } \\
\text { (Cervantes, Quijote, 2015, p. 651). }\end{array}$ & $\begin{array}{l}\text { Perch'io so che voi sete accorto e dotto, } \\
\text { ditemi, onde cavaste, o di qual razza, } \\
\text { quella bestiaccia stravagante e pazza, } \\
\text { Varchi, che voi vi sete messo sotto? } \\
\text { Al portante, al galoppo, al passo, al trotto } \\
\text { sembra, tanto si storce e si diguazza, } \\
\text { l'alfana già di Dodon della Mazza, } \\
\text { o la giumenta del Piovano Arlotto. } \\
\text { Or che sete invecchiato ed arricchito, } \\
\text { cavalcherete un caval sì plebeo, } \\
\text { che voi paiate un cortigian fallito? } \\
\text { No, no, Varchi, un par vostro semideo } \\
\text { vuole un corsiere aver vago e pulito, } \\
\text { come quel di Pitagora o d'Orfeo, } \\
\text { che di greco in caldeo } \\
\text { dirivi o sia di casa Chiaramonte, } \\
\text { da tre balzano ed abbia stella in fronte } \\
\text { e le fattezze pronte, } \\
\text { destro, animoso, leggero e gagliardo, } \\
\text { come fur già Brigliadoro e Baiardo. } \\
\text { Allor v'arà riguardo, } \\
\text { come vi si convien meritamente, } \\
\text { e stupirà di voi tutta la gente, } \\
\text { dicendo: «Finalmente! } \\
\text { Ecco che pur si vede alla presenza } \\
\text { la gloria di Parnaso e di Fiorenza» } \\
\text { (Grazzini, Rime, 2015, pp. 32-33). }\end{array}$ \\
\hline
\end{tabular}

No parece casual la coincidencia, no en vano se está hablando en ambos de un caballejo que desmerece por su aspecto a quien lo monta, cuando en realidad el jinete se merece algo mejor que sea capaz de vencer a otros caballos famosos. Tampoco parecen casuales algunas actitudes que se dan en la poesía burlesca de ambos autores, particularmente aquellas que se dedican a fustigar a los pedantes y a los académicos, ya sean italianos o españoles. 


\section{LAS NOVELAS}

La influencia del autor italiano en el español se puede apreciar también, según mi opinión, en algunas de sus novelas. Es muy probable que el carácter de literato cómico de Grazzini interesara a Cervantes, que pudo leer su obra e incluso alcanzar a ver alguna representación de sus comedias. Aunque no se suele señalar entre sus fuentes, creo que no hay ninguna duda del conocimiento directo de este autor, especialmente de sus novelas, como muestra en El celoso extremeño o en el entremés El viejo celoso, que creo que tienen un antecedente en la novela décima de la primera cena de Grazzini. He aquí un breve cuadro comparativo:

\begin{tabular}{|c|c|}
\hline $\begin{array}{c}\text { Grazzini, Le cene, prima cena, } \\
\text { novela } \mathrm{X}\end{array}$ & Cervantes, El celoso extremeño \\
\hline El protagonista: Ser Anastagio & El protagonista: Carrizales \\
\hline Vecchio & Viejo \\
\hline venne col tempo rico & se hace rico con el tiempo \\
\hline non avendo a chi lasciare & $\begin{array}{l}\text { quisiera tener a quien dejar sus bienes, } \\
\text { después de sus días }\end{array}$ \\
\hline deliberò di tor moglie & $\begin{array}{l}\text { Parecíale que aún podía llevar la carga } \\
\text { del matrimonio }\end{array}$ \\
\hline $\begin{array}{l}\text { fanciulla giovane, nobile e bella (Fiam- } \\
\text { metta) }\end{array}$ & $\begin{array}{l}\text { Doncella... de trece a catorce años... } \\
\text { agradable rostro y tan hermosa... de pa- } \\
\text { dres nobles (Leonora) }\end{array}$ \\
\hline «il piu geloso uomo del mondo» & «el más celoso hombre del mundo» \\
\hline $\begin{array}{l}\text { più sollecitudine e cura teneva in ben } \\
\text { guardarla }\end{array}$ & Casarme he con ella; encerrarela \\
\hline $\begin{array}{l}\text { Fragli quello... che nos arebbe mai pen- } \\
\text { sato di fare }\end{array}$ & $\begin{array}{l}\text { el encerramiento la lleva a hacer lo que } \\
\text { no quiere }\end{array}$ \\
\hline conoce a un joven médico (Giulio) & conoce a un joven virote (Loaysa) \\
\hline Trovar via e modo a i suoi piacieri & $\begin{array}{l}\text { Se las arregla para darle entrada en la } \\
\text { casa }\end{array}$ \\
\hline comete adulterio & $\begin{array}{l}\text { yacen juntos (adulterio en El viejo celo- } \\
\text { so) }\end{array}$ \\
\hline el marido tiene un accidente mortal & el marido enferma al enterarse \\
\hline $\begin{array}{l}\text { acuden el padre de la mujer y sus herma- } \\
\text { nos }\end{array}$ & llama a los padres de la mujer \\
\hline testa en favor de su esposa & testa en favor de su esposa \\
\hline $\begin{array}{l}\text { aconseja que si se casa y tiene un hijo, } \\
\text { le ponga su nombre }\end{array}$ & aconseja que se case con aquel mozo \\
\hline una criada vieja & la criada vieja Marialonso \\
\hline Anastagio muere & Carrizales muere \\
\hline Fiammetta, rica, se casa con el médico. & Leonora, rica, entra en un convento. \\
\hline
\end{tabular}


Por supuesto que no estoy diciendo que la fuente única de la novela cervantina sea esta pequeña narración de Grazzini, pero no se pueden obviar sus puntos en común. Aun así, conviene señalar el mucho mayor desarrollo de la novela de Cervantes, que tiene ingredientes insuperables como obra de arte literaria que no están en este posible modelo italiano. Todo aquello de los celos enfermizos, el que no haya ni gatos ni perros por el mero hecho de ser de género masculino, etc. es una hipérbole que se debe al buen hacer de Cervantes, que también podía haber tenido presente, posiblemente, otros modelos, italianos o no.

También elude detalles presentes en la obra de Grazzini, como que la mujer tome parte activa en el engaño del marido, al que hace salir de casa con el pretexto de que le busque medicinas, porque finge morirse, mientras su vecino el médico y ella se gozan en su propio lecho. Evidentemente los propósitos de Grazzini y Cervantes no son los mismos, este último busca la ejemplaridad, como sabemos, el castigo del viejo celoso y egoísta que se comporta de forma antinatural con su esposa y la encierra en vida. También el castigo de la joven, que tiene que elegir la vida conventual como purga de una relación extramatrimonial. A Grazzini no le importa nada de eso y se recrea, como antes Boccaccio, en el goce sexual de los jóvenes, que no tienen escrúpulo en engañar al marido viejo.

\section{LAS COMEDIAS}

Ni los poemas ni las novelas son los únicos textos de este autor italiano que pueden haber influido en Cervantes. Hay que considerar también sus comedias. Concretamente, hay un episodio cervantino que quiero analizar ahora, el de «la endemoniada fingida» en el Persiles (finales del libro III), del que se suele decir que su fuente es una novela italiana. Pero dicha fuente no se localiza, como podría parecer, en Boccaccio, Bandello, Cintio o Straparola, está de nuevo en nuestro Grazzini, il Lasca, que representa y publica la comedia titulada La spiritata en 1560. En ella sucede prácticamente lo mismo que en este episodio del Persiles ${ }^{3}$.

Las semejanzas son también evidentes, como muestra su argumento, bien resumido por José Enrique López Martínez (2014) en un importante trabajo, donde señala las deudas de Lope con Grazzini y de paso apunta la vinculación del episodio del Persiles con nuestro autor:

La comedia La Spiritata gira enteramente alrededor de dos embustes que una pareja de jóvenes ingenia para evitar que la dama sea desposada con su tío, como desea su padre: por una parte, fingir que la casa del padre de su amado está tomada por espíritus (engaño que eventualmente servirá para

3. Agradezco a Luana Bermúdez, colega de la Universidad de Ginebra, el haberme llamado la atención sobre esta relación en particular. 
robarle un arca con dinero); por otra, fingir que ella misma, Maddalena, está poseída por un espíritu que exige como condición para abandonarla el que ella se case con su querido Giulio. Paradójicamente, el tema central del fingimiento de la fanciulla no se representa nunca en escena, y solamente es referido por otros personajes que hacen constar detallada experiencia de los estragos que hace el «espíritu» en Maddalena (2014, p. 58).

A ello habría que añadir que Maddalena está enamorada del joven Giulio. El viejo Giovangualberto, padre de este, quiere ganar dinero con la boda de su hijo, pero Giulio en realidad está enamorado y compinchado con la joven. Por su parte, Niccodemo, padre de Maddalena, tiene un problema económico. Al final, la posesión diabólica se resuelve en boda, los padres de los jóvenes quedan contentos y el problema económico se soluciona.

El argumento recuerda claramente el episodio de la endemoniada fingida del Persiles: a Luca, pequeña ciudad italiana cercana a Florencia, ha llegado camino de Capua, donde se va a casar, la joven Isabela Castrucho con un tío suyo, el cual la quiere casar contra su voluntad y seguramente por conseguir un trato ventajoso. Ella está enamorada de Andrea Marulo, un joven italiano al que ha conocido en España y al que tiene avisado que venga a reunirse con ella en esa ciudad italiana. Para evitar la boda, Isabela se finge endemoniada, y advierte que solo mediante el matrimonio con Andrea conseguirá sacarse el demonio del cuerpo. Así es: llega Andrea, que parece por lo menos loco por su manera de actuar, y ambos se casan, supuestamente de mentira, y la joven sana. Unos sacerdotes, que habían acudido a la casa para exorcizar a la pobre Isabela, confirman sin embargo la validez del matrimonio, como el que se produce en el episodio de Basilio y Quiteria en el Quijote. El tío de la joven muere a consecuencia del desengaño y su entierro coincide con la boda de Isabela y con el bautizo de otro hijo del padre de Andrea, algo desconcertante porque lo imaginamos un viejo. Maurice Molho y otros críticos sostienen que en realidad el hijo que se bautiza lo es de Andrea e Isabela, y que por aquello de qué dirán se hace pasar por hermano del primero. Lo mismo que sucede, si reparamos, en la novela La fuerza de la sangre, cuando Leocadia resulta embarazada sin haberse casado con el joven que la deshonra.

Evidentemente, hay también algunos elementos que no coinciden: mientras Isabela es prácticamente la dama tracista en terminología teatral, Maddalena es pasiva y no aparece sino al final de la comedia. Cervantes añade además un componente literario, que falta en su modelo: Andrea Marulo irrumpe en el cuarto en que está su amada contrahaciendo un famoso romance: "Afuera, afuera, aparta, aparta», en que cambia al protagonista, el valeroso Muza, por su propio nombre. Ello lleva a pensar que está tan loco como la propia Isabela y suscita la frase más cómica del episodio: «¿Úsase en este pueblo que se case un diablo con otro?» (Cervantes, Persiles, 2004: p. 623).

Todo ello nos lleva a pensar que el germen del episodio cervantino es esta comedia de Grazzini, pero es evidente que tuvo que incorporar otros muchos elementos que transforman y adaptan la historia de la endemoniada fingida. 
Porque Cervantes mejora su fuente, y hace recitar a Isabela los versos del romance: «La mañana de san Juan / al tiempo que alboreaba», cuando alude a que conoció a Marulo cogiendo guindas en Illescas, lo cual puede ser indicio de locura para algunos (los viejos: su tío y el padre de Marulo), pero cobra sentido para los demás cuando sabemos que ello alude al enamoramiento de los jóvenes en la noche más mágica del año. Igualmente, a la llegada del joven enamorado este recita los versos ya mencionados: «Afuera, afuera, aparta, aparta, que entra el valeroso Andrea», lo cual puede ser parodia también de un inicio de romance en que el nombre del moro es Muza y el autor, muy probablemente, Lope de Vega, que lo utiliza mucho entre sus obras (Lozano Renieblas 1998: 56-57).

La acción del episodio, como digo, se sitúa en Luca, una ciudad italiana cercana a Florencia, que aparece más veces en la obra cervantina, por cuanto encontramos casi la misma descripción de la ciudad en El licenciado Vidrie$r a$, lo cual nos puede dar una pista del origen italiano del episodio ${ }^{4}$.

Si no fuera por la muerte con que se remata, que deja mal sabor de boca, todo nos podría llevar a pensar en un entremés (pero en un entremés el tío habría resultado simplemente burlado y chasqueado, como ocurre con el viejo de La cueva de Salamanca o El viejo celoso) (Zimic 2005: 182). Y hasta la dicha situación del mismo a finales del libro tercero del Persiles parece propia de este tipo de piezas entremesiles; pero seguramente Cervantes tuvo que adaptar el episodio a su narrativa para que no se le quedara en el cajón de las historias que no llegarían al público. El caso es que hoy nos da la pista para aventurar que Cervantes pudo basarse en Grazzini y tal vez habrá que seguir investigando la relación entre ambos autores para descubrir alguna nueva coincidencia.

Terminamos como el propio Cervantes en su última obra:

Adiós, gracias; adiós, donaires; adiós, regocijados amigos, que yo me voy muriendo y deseando veros presto contentos en la otra vida (Cervantes, Persiles, 2004, p. 123).

Que puede recordar aquellos otros versos del Lasca:

Addio, Febo; addio, Muse; addio, addio; / addio, voi rime, voi versi e voi prose / petrarchesche, burlesche ed amorose / restate in pace e fatevi con Dio (Grazzini, Rime, 2015, p. 91).

4. Nerlich (2005: 540-550) intenta documentar a quién pueden corresponder históricamente los nombres de Andrea Marulo (acaso trasunto de un tal Marco Marulo, algo relacionado con el erasmismo) y Castrucho, que correspondería a un jefe local de los gibelinos. Luca sería una ciudad más cercana a España y enfrentada al poder papal y a los güelfos. Es posible, como posible es el juego de palabras con los nombres de los personajes, que podrían aludir a Castrado (Castrucho) y capón (Capua). 


\section{FUENTES}

Cervantes, Miguel de (2004). Los trabajos de Persiles y Sigismunda, Carlos Romero Muñoz (ed.). Madrid: Cátedra.

Cervantes, Miguel de (2015). Don Quijote de la Mancha, Francisco Rico (ed.). Madrid: Real Academia Española.

Grazzini, Anton Francesco (1793). La prima e la seconda Cena. Novelle di Antonfrancesco Grazzini, detto il Lasca. Londra: Riccardo Bancker. Tomo primo.

Grazzini, Anton Francesco (1815). Le Cene di Antonfrancesco Grazzini, detto il Lasca. Volume terzo. Milano: Giovanni Silvestri.

Grazzini, Anton Francesco (1857). Le Cene ed altre prose di Antonfrancesco Grazzini, detto il Lasca. Firenze: Felice Le Monnier.

Grazzini, Anton Francesco (1859). Commedie di Antonfrancesco Grazzini, detto il Lasca, riscontrate sue migliori codici e postillate da Pietro Fanfani. Firenze: Felice Le Monnier.

Grazzini, Anton Francesco (2015). Le rime burlesche edite e inedite, per cura di Carlo Verzone. Banca di dati Nuovo Rinascimento. Accesible en $<$ http://www.nuovorinascimento.org>.

\section{BIBLIOGRAFÍA CITADA}

López Martínez, José Enrique (2014). «Locos y bobobos fingidos: otra forma de representar (sin disfraz) en el teatro de Lope de Vega», Atalanta. 2 (1), pp. 54-96.

Lozano Renieblas, Isabel (1998). Cervantes y el mundo del Persiles. Alcalá de Henares: Centro de Estudios Cervantinos.

Nerlich, Michael (2005). El Persiles descodificado o la divina comedia de Cervantes. Madrid: Hiperión.

Martin, Adrienne Laskier (1991). Cervantes and the Burlesque sonnet. Berkeley: University of California Press.

Pignatti, Franco (2014). Cinquecento plurale. Bibliografia. Antonfrancesco Grazzini. Accesible en $<\mathrm{http}$ //www.nuovorinascimento.org/cinquecento/grazzini.pdf $>$.

Werner, Inge (1973). Antonfrancesco Grazzini il Lasca (1505-1584) and the Burlesque. Tesis doctoral. Universiteit Utrecht. Accesible en <http://dspace.library.uu.nl/handle/1874/33804>.

Zampini, Tania (2013). Sole e Ombra: A study of sixteenth century humourism and grotesque through the works of Antonfrancesco Grazzini, l'accademia degli Humidi, and l'accademia degli Infiammati. Tesis doctoral. Baltimore: Johns Hopkins University.

Zimic, Stanislav (2005). Cuentos y episodios del Persiles. Pontevedra: Mirabel. 